\title{
RESEARCH PAPER \\ Unveiling Peruvian organic consumers demand for organics: A latent class approach
}

\author{
Angie Higuchi, and Jorge Dávalos \\ Universidad del Pacífico, Facultad de Ciencias Empresariales, Av. Salaverry 2020, Lima 11, Jesús María, \\ Lima, Perú.
}

\begin{abstract}
A. Higuchi, and J. Dávalos. 2016. Unveiling Peruvian organic consumers demand for organics: A latent class approach. Cien. Inv. Agr. 43(3): 408-417. This paper seeks to identify the consumer segments that constitute the market for organic products in Metropolitan Lima, Peru. The employed classification methodology, Latent Class Analysis, is implemented within a structural framework that is capable of identifying key relations such as the link between educational attainment and organic product consumption. This study builds on primary data gathered at the study site involving interviews with 547 organic consumers at a limited number of bio-fairs and bio-shops. Our results identify two segments: core and middle-level consumers. Although both segments exhibit similar concerns towards the environment, healthiness and tastiness, the core level exhibits higher preferences for the remaining attributes, controlling for demographical variables. Finally, this research provides evidence that educational attainment increases the likelihood of being a middle-level organic consumer.
\end{abstract}

Key words: Attributes, latent class analysis, Metropolitan Lima, organic consumers, Peru, socio-economic characteristics.

\section{Introduction}

Organic agriculture has proven to be beneficial for the development of regional markets (Flores, 2014). Latin America's role as a supplier of organic products is also undeniable. Nevertheless, only a few countries have produced national-level estimates of volume sales (Andrade Ortiz and Flores, 2008). Availability and supply scarcity, a lack of trust, and a shortfall of knowledge regarding the product and the price premium have been found to be major constraints to the growth

Received May 10, 2016. Accepted September 28, 2016.

Corresponding author: a.higuchi@up.edu.pe of the organic market (Stolz et al., 2011). Thus, most Latin American organic products have been sold in external markets with non-added value.

According to Flores (2014), Latin American domestic organic markets are being developed in every country, and the most popular farmers' fairs are being consolidated in many places. For instance, despite the economic crisis between 1996 and 2008, employment in the Mexican organic sector increased $26 \%$ per year (Salgado-Beltrán et al., 2013). An important well-known situation is that Brazil has the largest organic market in the region and that Costa Rica and Argentina's domestic markets are growing through farmers' 
fairs (FIBL and IFOAM, 2014). Additionally, households from Ecuador shop organics mainly at supermarkets, followed by fairs and specialized shops (Andrade Ortiz and Flores, 2008). In the particular case of the Peruvian organic domestic market, the year-on-year percentage growth is stimulated by the gastronomy movement, which has been contributing to the steady growth in local demand for high quality ecological and indigenous food (FIBL and IFOAM, 2014).

The literature identifies several factors as determinants of the consumption of organic products. From one perspective, in recent years, consumers have increased their health awareness, which in turn has increased their preference for organic food products (Goetzke et al., 2014). In contrast, evidence suggests the importance of intrinsic motivators that may drive most of the organic consumption behavior (Denver and Jensen, 2014). There is also a wide variety of psychological motives, such as sensory appeal, healthiness, and convenience, that underlie everyday food choices (Pula et. al., 2014). This considerable quantity of research was motivated by the important recent growth of the organic food product market (Hughner el al., 2007). Nonetheless, very few studies regarding organic products consumption have been conducted in Peru. Understanding the motivations that drive organic consumption should allow both private and public decision makers to better define consumer profiles to support more efficient matching between supply and demand (Idda and Pulina, 2008).

Hence, this paper's goal was to investigate two objectives: first, to identify the motives and attitudinal factors that best describe consumer segmentation within the organic products market in Metropolitan Lima while controlling for demographical variables, and second, to provide new evidence, such as the connection between educational attainment and organic product consumption. Both objectives were achieved by implementing a probabilistic clustering methodology that considers segmentation to be random.
Such specification leads to a more accurate statistical inference compared to the traditional cluster analysis approaches.

\section{Materials and methods}

Metropolitan Lima was chosen as the study site of this research because it is the fifth most populated city in Latin America. A choice-based sampling was used because this approach precludes making more general inferences regarding a larger population (Thompson and Kidwell, 1998), particularly with unknown organic consumer population weights. Primary data were gathered between April and November 2014 and between May and June 2015 at a representative number of bio-fairs (Mercado Saludable de La Molina and Ecoferia Lima) and bio-shops (Campos de Vida and Vacas Felices) in Metropolitan Lima. The structured questionnaire was administered with the support of El Mercado Saludable de La Molina and students from the Universidad del Pacífico, involving 547 consumers who consume organic products. The minimum sample size for this study was calculated according to the following assumptions: Modern Metropolitan Lima population (A and B); sampling error of 5\%; and 95\% confidence interval. The topics included on the survey questionnaire were the result of the combination of several surveys that were developed to assess the socio-demographic characteristics of households, including age, income, marital status and family size, and manifest variables, which are binary indicators (see Table 1).

The structural relations of our variables are represented by the Latent Class model i.e., a Latent Class Analysis (LCA). This approach enables the simultaneous identification of the characteristics that differentiate organic-consuming households and the values that these consumers derive from the attributes that they appraise regarding purchasing organic products in Metropolitan Lima. LCA can be briefly described as a categorical latent variable model whose indicators are either categorical or 
Table 1. Latent class variable descriptions.

\begin{tabular}{|c|c|c|}
\hline Variables & Scale & Description \\
\hline \multicolumn{3}{|l|}{ Continuous variables } \\
\hline Org consumption & Continuous & Consumption of organic products (years) \\
\hline Org share & Continuous & Share of organic on total expenditure (percentage) \\
\hline \multicolumn{3}{|l|}{ Control variables $\mathrm{X}(1)$} \\
\hline Education & Continuous & Consumer education (years) \\
\hline Age & Continuous & Age of the consumer (years \\
\hline \multicolumn{3}{|l|}{ Control variables $\mathrm{X}(2)$} \\
\hline Employed & Binary & Being employed or not $(\mathrm{Yes}=1$ or $\mathrm{No}=0)$ \\
\hline $\mathrm{HH}$ size & Continuous & Household size (number of members within a family) \\
\hline \multicolumn{3}{|l|}{ Indicators $\mathrm{Y}(1)-\mathrm{Y}(12)$} \\
\hline Vegetables & Binary & Interested in buying vegetables, fruits and eggs. \\
\hline Health awareness & Binary & Considers that organic products benefit health. \\
\hline Healthiness & Binary & Main reason for buying organic products is to stay healthy \\
\hline Environment & Binary & Considers that organic products benefit the environment. \\
\hline Taste & Binary & Considers that the organic product is tasty. \\
\hline Certification & Binary & Considers that the product bought is certified. \\
\hline Trustworthy & Binary & Considers that the organic product bought is trustworthy \\
\hline Price-quality & Binary & Considers that prices are fair relative to the quality of the product. \\
\hline Learning & Binary & Learn about organic products from the producer. \\
\hline Information & Binary & Considers that the information received by the producers is precise. \\
\hline Convenience & Binary & Buying at the Bio-fairs or Bio-shops is considered as convenient \\
\hline Type mkt & Binary & Bio-fairs (1) and Bio-shops (0) \\
\hline
\end{tabular}

continuous. LCA casts heterogeneity as a discrete distribution by using a specification based on the concept of endogenous (or latent) preference segmentation (Wedel and Kamakura, 2000). The approach depicts a population as consisting of a finite and identifiable number of segments or groups of individuals. Preferences are assumed to be relatively homogeneous within segments but to differ substantially across segments (classes). The number of segments (classes) is determined endogenously by the data. The probabilistic slotting of an individual into a specific segment depends on the perceptions and attitudes of the organic respondents (Kikulwe et al., 2009).

By analogy to factor analysis, LCA requires the specification of a set of indicators from which to identify the underlying latent class. Additionally, LCA is preferred to traditional clustering methods because it not only allows classification but primarily because it provides the tools for statistical inference, i.e., hypothesis testing and confidence interval estimation. Although data mining methods such as K-means clustering and hierarchical clustering are focused on classification accuracy, LCA models a probabilistic data generating process (PDGP). Thus, a priori information (i.e., theoretical relations) can be integrated into the PDGP to retrieve a probabilistic classification.

The model's estimates of the probability of observing a given attitude, given a latent class membership, provide evidence for statistical profiling. It should be noted that the model is a slight variation of a MIMIC (Multiple Indicators, Multiple Causes) model. Under such a framework, X(1) would be the vector of multiple causes (socio-economic characteristics), and the binary and continuous indicators represent multiple indicators. Figure 1 shows the causal relations implied by our LCA, where $\mathrm{Y}(\mathrm{i})$ represents every i-th indicator, ' $\mathrm{C}$ ' 
represents the binary latent class, and ' $\mathrm{X}(1)$ ' and ' $\mathrm{X}(2)$ ' are vectors of individual characteristics.

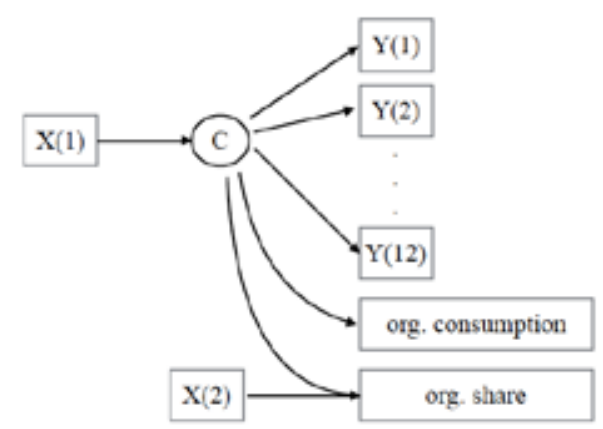

Figure 1. Structural relations.

Organic product consumption in years and a high organic share on total expenditure (percentage) should be suitable signals of the presence of core consumers within the sample. Thus, two continuous indicators were included in the model: Organic consumption (Org consumption) and organic share (Org share). Control variables (X(1) and $\mathrm{X}(2)$, respectively) were included in the model to isolate the genuine effect of belonging to a specific segment of organic consumers. Socio-economic $\mathrm{X}(2)$ variables, such as being employed (Yes $=1$ or $\mathrm{No}=0$ ) and having a smaller household size, would positively affect the organic share. Conversely, by including the education variable in model $\mathrm{X}(1)$, we sought to estimate whether consumers' educational attainment has a positive effect on the likelihood that an individual will belong to one segment or the other. Age was also included within $\mathrm{X}(1)$ as a proxy of health concerns to determine whether it has an effect on the organic consumer segmentation. Finally, the set of indicators noted as ' $\mathrm{Y}$ ' were selected by their ability to capture subjective attitudes towards the consumption of organic products ( $\mathrm{Y}(1)$ to $\mathrm{Y}(12)$ ). Thus, the latent classes that underlie such indicators would provide an estimate of the segmentation within the organic product consumers' market in Metropolitan Lima. Table 1 provides a description of the continuous variables "org consumption" and "org share", the control variables (X(1) and $\mathrm{X}(2))$ and the indicators $(\mathrm{Y}(1)$ to $\mathrm{Y}(12))$ retained in the analysis.

\section{Results and discussion}

First, an exploratory LCA is implemented for a maximum of four segments to estimate the most likely number of latent classes for our data. Then, consumer's profiles are defined based on the chosen latent class model. The number of classes in a choice is usually based on goodness of fit statistics such as the Akaike Information Criterion (AIC) or the Bayesian Information Criterion (BIC). Classification accuracy is assessed by the 'relative entropy' statistic (Ramaswamy et al., 1993), whereas the empirical identification and convergence of the ML estimation are assessed by the 'condition number'. The latter is defined as the ratio between the lowest and the highest eigenvalue of the Maximum Likelihood estimator's Hessian matrix.

Table 2 shows the low performance of the models that assume a number of latent classes greater than two. The condition number of these cases was excessively small, which implies the models' lack of empirical identification; i.e., the data patterns implied by the indicators do not allow the identification of either three or four latent segments (Kikulwe et al., 2009). Because one model offers a reliable estimation, that is, the one with two latent classes, there is no need to compare rival models based on their goodness of fit. Thus, information criteria (AIC and BIC) are reported here but are not interpreted.

To assess whether our model $\left(2^{*}\right)$ converges to a global maximum, alternative estimations were performed using numerous random starting values (20). It was verified that most of the random starting values led to the same ML estimator, which implies that our estimates converge to a global ML solution. Additionally, the relative entropy statistic (between zero and one) of approximately $60 \%$ reflects an accurate classification of individu- 
als (Ramaswamy et al., 1993). The 547 organic consumers were then assigned to a segment based on the estimated classification probabilities. Using this procedure, it was found that $51 \%$ of the sample belongs to the first segment and $49 \%$ belongs to the second.

The Hartman Group (2008), in its report, "The Many Faces of Organic", classifies organic buyers into three categories: core, mid-level and periphery. Similarly, the Natural Marketing Institute (NMI) classifies consumers by their level of interest in products that promote health and environmental safety. Table 3 contains the classifications and definitions of organic consumers proposed by the Hartman group and the NMI and the results obtained for profiling the two segments derived from this research (core and middle-level).

A wide body of literature has been produced on the theme of consumer demand for organic food. Most studies have focused on the relations among consumer characteristics, product attributes and organic food consumption tendencies (Idda and Pulina, 2008). A review of the socio-economic variables that have been used to study the influence of various factors on the behavior of specific groups of people (Füsun Tathdil et. al., 2009) suggested including demographic characteristics in the model's explanatory variables. Studies using socio-economic profiling have found that demographic characteristics are effective in describing the typical organic consumer (Hjelman, 2011). Nevertheless, previous studies have rarely used control variables as demographic characteristics to insulate the authentic effect of belonging to a specific group or segment of organic consumers. Table 4 presents the latent class probit and continuous indicators estimating equations with control variables (X(1) and $\mathrm{X}(2)$ ), which included the socio-economic characteristics noted in Table 1 (Latent class variable descriptions).

When testing the hypotheses, we included the control variables being employed, household size, age and education. Regarding the length of time of organic product consumption, consumers exhibit a non-significant differential between 3.76 and 3.97 years for the core and middle-level, respectively; i.e., both tend to have been in the

Table 2. Number of latent class and identification.

\begin{tabular}{lccccc}
\hline Latent Classes & Binary Indicators & Akaike (AIC) & Bayesian (BIC) & Condition Number & Entropy \\
\hline $2^{1}$ & 12 & 10617.8 & 10772.3 & $5.6 \mathrm{E}-06$ & 0.602 \\
$3^{2}$ & 12 & 10395.0 & 10615.7 & $3.01 \mathrm{E}-7$ & 0.7 \\
$4^{2}$ & 12 & 10140.2 & 10427.1 & $1.6-07$ & 0.75 \\
\hline
\end{tabular}

${ }^{1}$ No threshold has been restricted.

${ }^{2} \mathrm{ML}$ estimation is not empirically identified, and thresholds have been restricted.

Table 3. Organic consumer from the metropolitan area of Lima market segments profiled with the theory proposed by the Hartman Group and NMI.

\begin{tabular}{llll}
\hline Classification & Segment 1: Core & & Segment 2: Middle level \\
\hline $\begin{array}{l}\text { Hartman Group } \\
\text { N.M.I. }\end{array}$ & $\begin{array}{l}\text { Core level } \\
\text { Lifestyles of health and } \\
\text { sustainability (LOHAS) }\end{array}$ & Internal middle level & External middle level \\
Description & $\begin{array}{l}\text { Concern about health, quality, } \\
\text { taste and nutritional level, } \\
\text { among other issues. Engaged } \\
\text { and passionate about organic } \\
\text { products. }\end{array}$ & $\begin{array}{l}\text { Care about environmental issues } \\
\text { and the benefits of consuming } \\
\text { organics. They have a deeper, }\end{array}$ & $\begin{array}{l}\text { Consider variables as "proximity" } \\
\text { integrated approach to organics. } \\
\text { purpose of purchasing organic } \\
\text { products. Closer to the periphery } \\
\text { in the classification }\end{array}$ \\
\hline
\end{tabular}


organic market for similar periods. Household size and employment were introduced as socioeconomic control variables $(\mathrm{X}(2))$, i.e., to address a potential 'omitted variables' issue. It is expected that people who were employed were the ones who purchased organic products. This expectation arises because the difference in price between conventional and organic food (premium price) is often excessively large for conventional consumers (Falguera et. al., 2012). The employed variable is statistically significant at the $5 \%$ level. This may be natural because unemployed individuals who receive no income tend to have less demand for organic products. Similarly, larger households may encounter tighter budget constraints, which would unbalance the allocation between organic and non-organic product expenditures. Despite having the expected sign, the "HH size" variable was not statistically significant.

Evidence of the relationship between education and organic consumption is divergent. On the one hand, there is evidence of a strong connection between education and awareness of organic food benefits (Muhummad et. al., 2016). However, other studies related to organic product consumption and education found that higher levels of education decreased the willingness to pay for pest-free produce and ergo organics (Thompson and Kidwell, 1998; Govindasamy and Italia, 1999). Therefore, by including the education variable in model X(1), we seek to estimate the relation for our population of interest, i.e., Metropolitan Lima. As can be observed, the LC probit estimates verify the negative relation between education and the probability of being a core consumer. A possible explanation for this inverse relation is that more college-educated consumers tend to use their income for functional food, which is usually perceived as healthy (Goetzke et al., 2014). These products are enriched with substances such as probiotics, prebiotics or omega-3 fatty acids, which can be a less expensive substitute compared with organics. On the other hand, age was included in X(1) as a proxy of health concerns to determine whether it affects the organic consumer segmentation. The probit coefficients for segment one (potential core consumers) show that an individual's age (statistically non-significant) was not a key determinant of becoming a core consumer (Table 4).

The purchase of organic foods can be viewed as an action motivated by beliefs healthiness, good taste and positive impacts on the environment (Shafie and Rennie, 2012; Vega-Zamora et al., 2013). Therefore, once the control variables were evaluated, the probabilities and statistical comparison of the indicators $\mathrm{Y}(\mathrm{i})(\mathrm{i}=1$ to 12$)$ for the two-segment LCA (core and middle level consumers) were calculated as an authentic effect of belonging to a specific organic consumers group (bottom, Table 4). The null hypothesis of equality of both probabilities for every indicator was tested, and the mean of each binary (share) indicator was compared between the core and middle segments.

A slightly larger proportion of the potential core clients (first segment) purchase vegetables, fruits and eggs (57.6\%). At bio-fairs, the producers offer a range of products, including vegetables, tubers, fruits, pulses, grains and dairy products, on Saturdays and Sundays. Bio-shops in Lima offer multiple ecological products, such as medicine, food and clothing, in addition to services such as prepared food. Potential middle-level consumers (second segment) can complement their daily products that are not available at the supermarkets.

Many consumer studies regarding motivations for organic purchase have repeatedly shown that consumers often name health as the main reason to choose organic food because these products are free of pesticides, chemicals and other pollutant residues (Hjelmar, 2011; Lee and Yun, 2015). A wide range of research reveals health concerns to be the primary motivating factor that moves consumers to spend more of their food budgets on organic products (Shafie and Rennie, 2012). For instance, in Ecuador (Andrade Ortiz and Flores, 2008) and Mexico (Salgado-Beltrán et 
Table 4. Latent class and continuous indicator estimating equations.

\begin{tabular}{|c|c|c|c|}
\hline $\begin{array}{l}\text { Org. consumption } \\
\text { (dependent variable) }\end{array}$ & $\begin{array}{c}\text { Both } \\
\text { segments }\end{array}$ & $\begin{array}{c}\text { Core } \\
(\text { Segment } 1, \mathrm{C}=1)\end{array}$ & $\begin{array}{c}\text { Middle level } \\
\text { (Segment 2, C=2) }\end{array}$ \\
\hline \multirow[t]{2}{*}{ Intercept (mean) ${ }^{1}$} & & 3.974 & 3.766 \\
\hline & & $(0.416)$ & $(0.482)$ \\
\hline \multicolumn{4}{|c|}{ Org. share (dependent variable) } \\
\hline \multicolumn{4}{|l|}{$X(2)$ : } \\
\hline Employed $^{3}$ & 0.029 & & \\
\hline HH size & -0.004 & & \\
\hline \multirow[t]{2}{*}{ Intercept $^{1}$} & & 0.366 & 0.315 \\
\hline & & $(0.023)$ & $(0.023)$ \\
\hline \multicolumn{4}{|c|}{ Latent Class probit (Probability of being at segment 1 ) } \\
\hline \multicolumn{4}{|l|}{$\mathrm{X}(1)$ : } \\
\hline Age & -0.004 & & \\
\hline Education $^{2}$ & -0.097 & & \\
\hline Intercept $^{2}$ & +1.67 & & \\
\hline $\begin{array}{l}\text { Indicators } \\
\mathrm{Y}(1)-\mathrm{Y}(12)\end{array}$ & & $\begin{array}{c}\text { Core } \\
\text { (Segment } 1, \mathrm{C}=1)\end{array}$ & $\begin{array}{c}\text { Middle level } \\
\text { (Segment } 2, \mathrm{C}=2 \text { ) }\end{array}$ \\
\hline \multicolumn{4}{|l|}{ Consumer attitudes } \\
\hline \multicolumn{2}{|l|}{$Y(i)=1$} & \multicolumn{2}{|c|}{$(P[Y(i)=1 \mid C] \%)$} \\
\hline Vegetables $^{1}$ & & 57.6 & 55.9 \\
\hline Health awareness ${ }^{1}$ & & 32.6 & 31.6 \\
\hline Healthiness & & 99.3 & 90.4 \\
\hline Environment & & 99.6 & 80.4 \\
\hline Taste & & 98.5 & 78.2 \\
\hline Certification $^{1}$ & & 86.8 & 52.3 \\
\hline Trustworthy $^{3}$ & & 93.6 & 66.2 \\
\hline Price-quality ${ }^{3}$ & & 92.6 & 51.9 \\
\hline Learning $^{3}$ & & 93.9 & 58.2 \\
\hline Information $^{4}$ & & 96.7 & 67.7 \\
\hline Type mkt (Biofairs $=1)^{4}$ & & 82.9 & 88.9 \\
\hline Convenience $^{1}$ & & 92.7 & 70.8 \\
\hline
\end{tabular}

Note. The numbers shown in parentheses are the standard deviations.

${ }^{1}$ Significant at the $1 \%$ level; ${ }^{2}$ Significant at the $2.5 \%$ level; ${ }^{3}$ Significant at the $5 \%$ level; and ${ }^{4} 10 \%$ level of significance.

al., 2013), the main motivating factor to purchase organic products is health. Moreover, mainly to evaluate product attributes such as health, eight out of ten Mexican consumers have purchased organic food because of health (Salgado-Beltrán et al., 2013). Although the "health awareness" differential between the potential core (32.6\%) and middle-level consumers (31.6\%) appears to be narrow, it is statistically significant. Nevertheless, regarding "healthiness", potential core (99.3\%) and middle-level clients (90.4\%) exhibit a statistically non-significant differential; i.e., both consume organic products, driven primarily by the motivation of remaining healthy.

Product attributes associated with ecological welfare (i.e., environmental protection and animal welfare) also motivate consumers to choose organic food (Lee and Yun, 2015). Vega-Zamora et al. (2013) noted that the main reasons that consumers purchased and consumed organic foods were tied to perceived benefits such as quality and taste. In our findings, neither the "Environment" nor "Taste" variables exhibited significant differen- 
tials between core and middle-level consumers, which implies that these segments are highly and equally concerned about these variables. Their high commitment is reflected by their probabilities, which are higher than 0.78 for "taste" and "environment" in both latent segments.

Developing trust in the organic food supply requires tools such as quality certifications or labeling, which should be used as part of a communications strategy to add value to organic products and provide confidence to consumers (Hamzaoui-Essoussi et al., 2013). The term "organic" carries a positive connotation and, as such, can be assumed to be a heuristic cue or an indicator of perception (Vega-Zamora et al., 2013). Organic labeling is typically the means by which consumers distinguish organic food products from conventional offerings. This type of labeling is very helpful to a convenience consumer who is seeking clear, trustworthy (Hjelmar, 2011) and more comprehensive product information (Denver and Jensen, 2014). For instance, consumers perceive foods that are labeled organic as being healthier (Goetzke et. al., 2014) and safer (Vega-Zamora et al., 2013). In Canada, consumers expect that the quality is good and that the products are certified (Hamzaoui-Essoussi et al., 2013). It appears that the most important sales argument that is used to justify the price premium for organic foods is food safety (Shafie and Rennie, 2012). Consequently, a significant share of respondents in the potential core client segment gave higher values in the “certification" (86.8\%), "trustworthy" (93.6\%) and "price-quality" (92.6\%) variables (significant at 1 and $2.5 \%$, respectively) compared to those given by the potential middle-level client segment (52.3, 66.2 and 51.9\%, respectively).

Bio-fairs represent the possibility of buying and consuming weekly ecological products. In addition to the weekly supply of organic fairs, in Lima, other daily focus establishments exist, including bio-shops that share ecological, organic and healthy products. The bio-fair is characterized by generating an integration space between consumers and producers because of the affordable diffusion of concepts and the agro-ecological proposal. The continuous and direct assessment of producers improves the consumers' experience in these organic spaces. Thus, the "learning" and "information" indicators are 93.9 and $96.7 \%$ for potential core consumers compared with 58.2 and $67.7 \%$ for potential middlelevel consumers, respectively (both differentials are statistically significant at 10 and $2.5 \%$, respectively). Moreover, our results suggest that relative to middlelevel consumers, core consumers are more prone to visit bio-shops than bio-fairs. This apparently counterintuitive result is probably explained by the difference in products' availability because bio-fairs are open solely on weekends, whereas bio-shops are open from Monday to Saturday. Given core consumers' higher demand, they need to purchase products at higher volumes or frequencies, which implies a greater need (relative to middle-level consumers) to access the market on weekdays to supply their households' cupboards.

Convenience behaviors characterize pragmatic organic consumers who expect organic foods to be available and clearly visible in local markets and to incorporate reflexive practices (health, ethical, political and quality considerations) (Hjelmar, 2011). Generally, consumers who use standard distribution channels are seeking convenience. Consumers are not particularly informed regarding what "organic" means and are usually confused regarding the difference between "organic" and "natural" products, which does not necessarily mean safe (Falguera et al., 2012). The "convenience" indicator exhibits a significant differential (at the 1\% level) between potential core consumers and middle-level consumers (approximately 92.7 and 70.8\%, respectively).

This research suggests that core consumers tend to be convinced that organic products are healthier, better tasting or fresher than conventional products. Moreover, health, taste and environmental safeguards are the main inherent reasons for purchasing organic food. The LCA identifies two clusters of organic respondents: 
core and middle-level consumers. Although both segments exhibit similar concerns towards the environment, healthiness and tastiness, core consumers exhibit higher preferences for sensory, quality and learning organic attributes, among others. Finally, this research provides evidence that educational attainment increases the likelihood of being a middle-level organic consumer.

\section{Acknowledgements}

We are very thankful to research assistants Hans Stehli Torrecilla, María Alejandra Padilla Blas and Jean Pierre Bolaños Hurtado. We also would like to express special thanks to the students of quantitative analysis for business (2014-2015) at Universidad del Pacífico.

\title{
Resumen
}

\begin{abstract}
A. Higuchi y J. Dávalos. 2016. Revelando las preferencias de los consumidores de productos orgánicos en Perú: un enfoque basado en el análisis de clases latentes. Cien. Inv. Agr. 43(3):408-417. La presente investigación tiene por objetivo identificar los segmentos de mercado de consumidores de productos orgánicos en Lima Metropolitana (Perú). Además, se implementa como metodología de clasificación el análisis de clases latentes, en conjunto con un marco estructural capaz de identificar relaciones clave, como por ejemplo el vínculo entre el nivel de educación y el consumo de productos orgánicos. La investigación se basa en información primaria recabada en el lugar de estudio, comprendiendo entrevistas con 547 consumidores de productos orgánicos en un número limitado de tiendas y ferias orgánicas. Los resultados muestran dos segmentos de consumidores, el segmento de nivel medio y el segmento de nivel central. A pesar de que ambos segmentos identificados poseen actitudes similares con respecto al medio ambiente, la salud y el sabor, el segmento de nivel central exhibe niveles de preferencia mayores en los atributos restantes, controlando los efectos de las variables demográficas. Finalmente, la investigación brinda evidencia de que dado un incremento en el nivel de educación, la probabilidad de ser clasificado como un consumidor de productos orgánicos de nivel medio aumenta.
\end{abstract}

Palabras clave: Análisis de clases latentes, atributos, características socioeconómicas, consumidores de productos orgánicos, Lima Metropolitana, Perú.

\section{References}

Andrade Ortiz, D., and M. Flores. 2008. Consumo de productos orgánicos/agroecológicos en los hogares ecuatorianos. VECO, Quito. 88 pp.

Denver, S., and J. D. Jensen. 2014. Consumer preferences for organically and locally produced apples. Food Quality and Preference 31: 129134.

Falguera, V., N. Aliguer and M. Falguera. 2012. An integrated approach to current trends in food consumption: Moving towards functional and organic products?. Food Control 26: 274-281.
Flores, P. (2014). Organic agriculture in Latin America and the Caribbean, principles of organic agriculture. FiBL-IFOAM. https:// www.fibl.org/fileadmin/documents/shop/1636organic-world-2014.pdf (accessed 26 May. 2015).

FIBL and IFOAM (2014). The principles of organic agriculture. FiBL - IFOAM. https://www.fibl. org/fileadmin/documents/shop/1636-organicworld-2014.pdf (accessed 26 May. 2015).

Füsun Tathdil, F., I. Boz and H. Tatlidil. 2009. Farmers perception of sustainable agriculture and its determinants: a case study in Kahramanmaras 
province of Turkey. Environment, Development and Sustainability 11: 1091-1106.

Goetzke, B., S. Nitzko and A. Spiller. 2014. Consumption of organic and functional food: A matter of well-being and health?. Research report. Appetite 77: 94-103.

Govindasamy, R., and J. Italia. 1999. Predicting willingness-to-pay a premium for organically grown fresh produce. Journal of Food Distribution Research 30: 45-53.

Hamzaoui-Essoussi, L., L. Sirieix and M. Zahaf. 2013. Trust orientations in the organic food distribution channels: A comparative sudy of the Canadian and French markets. Journal of Retailing and Consumer Services 20: 292-301.

Hartman Group. 2008. The many faces of organic: 2008. http://www.hartman-group.com/hartbeat/ organics-today-who-buying-and-what-next (accessed 13 Feb. 2015).

Hjelmar, U. 2011. Consumers' purchase of organic food products: A matter of convenience and reflexive practices. Appetite Journal 56: 336-344.

Hughner, R. S., P. McDonagh, A. Prothero, C. J. Shultz and J. Stanton. 2007. Who are the organic food consumers? A compilation and review of why people purchase organic food. Journal of Consumer Behavior 6: 94-110.

Idda, L., and P. Pulina. 2008. The motivational profile of organic consumers: a survey of specialized stores customers in Italy. Paper presented at the 12th congress of the European association of Agricultural Economics-EAAE, Vienna, Austria :

Kikulwe, E., E. Birol, J. Wesseler, and J. Falck-Zepeda. 2009. A latent class approach to investigating consumer demand for genetically modified staple food in a developing country: the case of GM bananas in Uganda. International Food Policy Research Institute. http://www.ifpri.org/sites/default/files/publications/ifpridp00938.pdf (accessed 19 Feb. 2015).

Lee, H.-J., and Z.-S. Yun. 2015. Consumers' perceptions of organic food attributes and cognitive and affective attitudes as determinants of their purchase intentions toward organic food. Food Quality and Preference 39: 259-267.
Muhummad, S., E. Fatherlrahman and R. Ullah. 2016. "The significance of consumer's awareness about organic food products in the United Arab Emirates". Sustainability 8: 833-844.

Natural Marketing Institute. 2013. NMI's sustainability segmentation quantifies what attracts people to sustainability. http://www.nmisolutions. com/index.php/syndicated-data/segmentationalgorithms-a-panels/lohas-segmentation (accessed 10 Dec. 2014).

Pula, K., C. D. Parks and C. F. Ross. 2014. "Regulatory focus and food choice motives: Prevention orientation associated with mood, convenience, and familiarity". Appetite 78: 15-22.

Ramaswamy, V., DeSarbo, W. S., Reibstein, D. J., and Robinson, W. T. (1993). "An empirical pooling approach for estimating marketing mix elasticities with PIMS data”. Marketing Science, 12(1), 103-124.

Salgado-Beltrán, L., J. E. Espejel-Blanco and L.F. Beltrán-Morales. 2013. Marketing mix influencing organic foods purchase of Mexican consumers. China- USA Business Review 12: 618-626.

Shafie, F. A., and D. Rennie. 2012. Consumer perceptions towards organic food. Procedia-Social and Behavioral Sciences 49:

Stolz, H., M. Stolze, U. Hamm and M. Janssen. 2011. Consumer attitudes towards organic versus conventional food with specific quality attributes. NJAS - Wageningen Journal of Life Science 58: 67-78.

Thompson, G. D., and J. Kidwell. 1998. Explaining the choice of organic produce: cosmetic defects, price and consumer preferences. American Journal of Agricultural Economics 80: 277-287.

Vega-Zamora, M., and F. J. Torres-Ruiz. 2013. The influence of the term 'organic' on organic food purchasing behavior. Procedia-Social and Behavioral Sciences 81:

Wedel, M. and Kamakura, W. A. (2000). "Market segmentation. Conceptual and Methodolical foundations". Second edition. Boston: Kluwer Academic Publishers. 